\title{
Soil Study of Woodland in Pirgulu State Nature Preserve of Azerbaijan
}

\author{
Ulviyya Mammadova
}

Department of Soils Ecology and Bonitation, Institute of Soilscience and Agrochemistry of ANAS, Baki, AZ1073, Azerbaijan

\begin{abstract}
Soil study was carried out in Pirgulu State Nature Preserve of Azerbaijan. In the preserve field studies were mainly realized for soils under woodland area. Due to the hectare, sections of soil have been done for taking soil samples. These samples were analyzed in lab condition, then according to the analysis results, current state of the preserve was determined. Finally new and first soil map of Pirgulu State Nature Preserve of Azerbaijan was established.
\end{abstract}

Keywords Soil Study, Soil Analysis, Soil Map

\section{Introduction}

Majorly brown soils extended in the area of Pirgulu State Nature Preserve. Several soil sub-types, sorts and kind diversities of brown soils are observed. On the horizon at the different height from sea level soil types (including sub-typ es) are characterized due to the extension areal and morpho genetic properties. The relief of the zone having mountain-brown soil type especially consists of sthenic lacerated mountains. Such soils allocate largely under oak-hornbeam forests with xerophilous grasses. The rocks formating the soil type are chalkstone, carbonated clay schist with buhr[1] and sand-stone, eluvial, eluvial - diluvium efflorescence productions. In the agriculture mountain-brown soil type has great importance for dry planting. In the regions where this soil type exists there is fruitful condition for grape farming, gardening, grain cropping. Pirgulu State Nature Preserve is the richest area with his soil cover. For sequence of soil foundation taxonomic units the climate and the landscape formatted by macro and meso-relief have particular significance. In mountainous condition in soil formation process lithologic and petrographic content of the pedogenic rocks is one of the main factors[2]. Eluvial, deluvium and alluvial rocks distribution regulation in the initial pedogenesis process shows itself in the soil profile spreading. Sometimes height of the slopes changes sharply in Pirgulu zone. It stands that slope gradient, slope facing, thickness of eolation shell, slope height and etc. indexes influences se riously on soil-formation process, soil spreading, soil variousness.

\section{Research Method and Object}

\footnotetext{
* Corresponding author:

uf_samadova@yahoo.com (Ulviyya Mammadova)

Published online at http://journal.sapub.org/re

Copyright (C) 2012 Scientific \& Academic Publishing. All Rights Reserved
}

In the studying region mainly mountain-meadow steppe and mountain-forest brown soils are met. Mountain-meadow steppe soils are characteristic to subalpine meadow steppes, this soil type extended on 1800-2000 m height in Pirgulu. At times mountain-meadow steppe soils make multiple mosaic concerning subalpine meadows together blackish mountain-meadow soils in the high mountainous zone in the preserve area. At the height of these soils extension aridity is observed in the climate showing. Average annual temperature $\left(8,5-11,1^{\circ} \mathrm{C}\right)$ is higher than the climate indexes of subalpine mesophile meadows. Plant cover of the region where these soils extended consists of meadow-steppes, different cereal crops phytocenosis. On the surface layers of soil decomposition of the organic matters happened more intensively than in subalpine meadow. Mountain-meadow steppe soils have some characteristics concerning to the steppe soil-formation type. Because of the external mood these soils look like to the blackish mountain-meadow soils, but this soil type distinguishes from the second one due to the physical-chemical properties and some pedogenesis[2] factors. Structure of this soil profile repeats blackish mountain-meadow soils from majority reasons. At the same time distinguished from the blackish mountain-meadow soils because of its turfing nature and depth, coloring range by humus, washing in depth and more developed profile. On upper $A_{1}$ horizon of this soil there is silicium oxide and one half oxides decreasing and their collection on $\mathrm{B}$ horizon relatively is observed. $\mathrm{SiO}_{2}$ is more at the alluvial horizon, silicium compositions migrate to the lower layers in soil-formation process. Except $\mathrm{A}_{0}$ in comparison with $\mathrm{SiO}_{2}$ iron, aluminum oxide[3] makes difference in the mineral parts of separate genetic horizons. Generally mountainmeadow steppe soils vahe been less investigated. One of the largest extended soils in the investigation area is brown mountain-forest soils. This soils type is characterized by its relative thick humus layer, clayey layer under humus horizon, good aggregation, clear carbonated- illuvial horizon. De- 
pending on surficial partition degree and the influence of the relief condition soil profile thickness changes on a large scale. The depth of the profile is often more than $50-60 \mathrm{~cm}$ on comparatively inclined, the southern and southern-east slopes. Frequently on upper surface with humus such carbonated compositions are observed. Respectively in mild elements[4] of the relief, notably on the northern-west and west slopes, brown soils extended having $110-150 \mathrm{~cm}$ profile depth as a rule. In the region on the mountainous and foothill fields stepped brown soils spreaded that's why here aride forest landscape is observed. In the zone of the preserve in prairie areas forest biodiversity is replaced into steppe formation, this causes grass creation on soil surface. Depending on the ecological-geographical condition of the region, physico-chemical properties of the soils, soil morphological structure, brown mountain-forest soil[5] has washed brown mountain-forest, typical brown mountain-forest, carbonated brown mountain-forest, stepped carbonated brown mountain-forest subtypes here. On the north slopes medium thick and thick soils developed. And on upper and middle parts of the south slopes soils having medium thickness and lamella skeleton exceed. In the apron part of the both on the south and the north slopes thickened profile soils[6] are frequently faced. In the investigation region mountain-meadow, mountain-forest zone surpass, it is cleared in soil type and sub-types formation.

Table 1. Analysis result of soil samples from woodland area in Pirgulu State Nature Preserve of Azerbaijan

\begin{tabular}{|c|c|c|c|c|c|c|c|c|c|c|c|c|c|c|}
\hline \multicolumn{2}{|c|}{ Soil sections } & \multirow[t]{2}{*}{$\mathrm{pH}$} & \multirow[t]{2}{*}{$\mathrm{CO}_{2}$} & \multirow[t]{2}{*}{$\mathrm{CaCO}_{3}$} & \multirow[t]{2}{*}{$\mathrm{Ca}$} & \multirow[t]{2}{*}{$\mathrm{Mg}$} & \multirow[t]{2}{*}{$\mathrm{Na}$} & \multirow[t]{2}{*}{$\mathrm{SAB}$} & \multirow[t]{2}{*}{ humus } & \multirow[t]{2}{*}{$\mathrm{N}$} & \multirow[t]{2}{*}{$\mathrm{P}$} & \multicolumn{2}{|c|}{$\begin{array}{c}\text { granulometric com- } \\
\text { position, with \% }\end{array}$} & \multirow{2}{*}{$\begin{array}{c}\text { hydroscopic } \\
\text { humidity, } \\
\text { with } \%\end{array}$} \\
\hline № & $\mathrm{cm}$ & & & & & & & & & & & $<0,001$ & $<0,01$ & \\
\hline \multicolumn{15}{|c|}{ Medium clayey, lamella, washed mountain-forest brown } \\
\hline \multirow{2}{*}{1} & $0-12$ & 6,7 & - & - & 32,50 & 17,50 & - & 50,00 & 4,18 & 0,21 & 0,18 & 7,84 & 33,94 & 3,1 \\
\hline & $12-27$ & 6,5 & - & - & 28,50 & 19,00 & - & 47,50 & 3,52 & 0,18 & 0,17 & 10,88 & 38,76 & 3,6 \\
\hline \multirow{3}{*}{18} & $0-6$ & 6,2 & - & - & 12 & 7,00 & 0,50 & 19,50 & 3,43 & 0,17 & 0,18 & 11,14 & 39,88 & 3,6 \\
\hline & $6-11$ & 6,4 & - & - & 15 & 6,00 & 0,60 & 21,60 & 2,99 & 0,14 & 0,16 & 8,66 & 35,96 & 3,7 \\
\hline & $11-29$ & 6,3 & - & - & - & - & - & - & 1,66 & 0,08 & 0,13 & 10,68 & 36,56 & 3,4 \\
\hline \multicolumn{15}{|c|}{ Heavy clayey, medium thick, washed mountain-forest brown } \\
\hline \multirow{3}{*}{13} & $0-11$ & 6,7 & - & - & 20,50 & 20,50 & - & 49,00 & 3,65 & 0,18 & 0,23 & 10,22 & 43,72 & 4,2 \\
\hline & $11-29$ & 6,5 & - & - & 19,50 & 19,50 & - & 47,00 & 3,20 & 0,16 & 0,21 & 19,34 & 46,64 & 4,4 \\
\hline & $29-42$ & 6,4 & - & - & 16,00 & 16,00 & - & 42,50 & 2,75 & 0,14 & 0,20 & 15,88 & 44,24 & 4,1 \\
\hline \multirow{3}{*}{14} & $0-10$ & 6,5 & - & - & 23 & 17,00 & - & 40 & 3,41 & 0,17 & 0,22 & 20,16 & 47,82 & 4,5 \\
\hline & $10-31$ & 6,7 & - & - & 20,50 & 16,50 & - & 40 & 3,08 & 0,15 & 0,19 & 12,56 & 45,26 & 4,2 \\
\hline & $31-49$ & 6,6 & - & - & 21,50 & 14,50 & - & 37 & 2,59 & 0,13 & 0,18 & 21,46 & 48,58 & 4,6 \\
\hline \multicolumn{15}{|c|}{ Heavy clayey, lamella, washed mountain-forest brown } \\
\hline 7 & $0-10$ & 6,6 & - & - & 24 & 17,00 & - & 41,00 & 3,42 & 0,17 & 0,20 & 17,58 & 45,28 & 4,3 \\
\hline 7 & $10-29$ & 6,4 & - & - & 23,50 & 16,50 & - & 40,00 & 2,85 & 0,14 & 0,16 & 18,00 & 43,00 & 4,1 \\
\hline 0 & $0-10$ & 6,7 & - & - & 22,50 & 18,00 & - & 40,50 & 3,82 & 0,19 & 0,15 & 19,08 & 44,26 & 4,2 \\
\hline 9 & $10-29$ & 6,8 & - & - & 18,50 & 15,00 & - & 33,50 & 3,05 & 0,15 & 0,11 & 11,00 & 36,44 & 3,4 \\
\hline & & & & & Ieavy cl & yey, mec & ium th & $\mathrm{k}$, typic & mountai & forest & & & & \\
\hline & $0-13$ & 6,8 & - & - & 20,50 & 16,50 & - & 43,00 & 4,06 & 0,20 & 0,22 & 20,30 & 49,42 & 4,7 \\
\hline 2 & $13-30$ & 6,6 & - & - & 29,00 & 19,50 & - & 48,50 & 3,65 & 0,18 & 0,20 & 21,72 & 51,16 & 5,00 \\
\hline & $30-42$ & 7,8 & 1,90 & 4,32 & 28,00 & 18,00 & 0,60 & 46,60 & 3,10 & 0,15 & 0,18 & 20,02 & 53,54 & 5,2 \\
\hline & $0-8$ & 6,6 & - & - & 17,00 & 17,00 & - & 43,00 & 3,24 & 0,16 & 0,18 & 12,16 & 40,48 & 3,8 \\
\hline 12 & $8-21$ & 8,1 & 2,85 & 6,48 & 16,50 & 16,50 & 0,70 & 42,20 & 2,91 & 0,14 & 0,16 & 11,18 & 44,42 & 4,1 \\
\hline & & & & & Light & clayey, 1 & mella, & jpical n & untain- $\mathrm{fc}$ & st brov & & & & \\
\hline 15 & $0-10$ & 8,1 & 4,49 & 10,34 & 28,00 & 18,50 & 0,80 & 36,00 & 2,73 & 0,14 & 0,21 & 20,16 & 55,48 & 5,2 \\
\hline 15 & $10-24$ & 8,3 & 5,66 & 12,86 & 22,50 & 16,00 & 1,00 & 46,80 & 2,22 & 0,11 & 0,19 & 23,48 & 56,24 & 5,4 \\
\hline & $0-8$ & 7,9 & 3,38 & 7,69 & 30,00 & 17,00 & 1,30 & 48,30 & 3,38 & 0,17 & 0,20 & 18,06 & 50,52 & 5,2 \\
\hline 17 & $8-17$ & 8 & 3,19 & 7,26 & 32,50 & 15,00 & 1,40 & 48,90 & 2.42 & 0,12 & 0,18 & 20,44 & 53,44 & 5,00 \\
\hline & $17-35$ & 8,1 & 3,57 & 8,12 & - & - & - & - & 1,56 & 0,08 & 0,15 & 19,20 & 51,34 & 5,3 \\
\hline & & & & & Heavy o & ayey, lar & nella, c & bonate & nountain & orest b & & & & \\
\hline & $0-12$ & 8,3 & 2,85 & 6,48 & 31,00 & 15,50 & 1,60 & 48,10 & 3,17 & 0,16 & 0,19 & 19,68 & 45,26 & 4,5 \\
\hline 16 & $12-29$ & 8,4 & 3,61 & 8,20 & 19,50 & 15,00 & 1,40 & 35,90 & 2,60 & 0,13 & 0,19 & 19,00 & 47,92 & 4,8 \\
\hline & $29-38$ & 8,5 & 4,35 & 9,91 & - & - & - & - & 2,12 & 0,11 & 0,17 & 18,16 & 49,16 & 5,1 \\
\hline & $0-11$ & 7,9 & 5,12 & 11,64 & 31,50 & 16,00 & 1,10 & 48,60 & 2,48 & 0,12 & 0,17 & 13,24 & 47,96 & 4,8 \\
\hline 19 & $11-23$ & 8 & 4,93 & 11,20 & 26,50 & 15,50 & 0,90 & 42,90 & 1,54 & 0,08 & 0,17 & 20,16 & 49,76 & 4,7 \\
\hline & $23-37$ & 8,1 & 5,66 & 12,86 & - & - & - & - & 1,08 & 0,05 & 0,11 & 21,14 & 52,84 & 5,3 \\
\hline & & & & & ght clay & mediu & $\mathrm{n}$ thick & carbona & mount & -fores & own & & & \\
\hline & $0-10$ & 8,0 & 2,85 & 6,48 & 25,00 & 16,50 & 1,60 & 43,10 & 3,16 & 0,16 & 0,19 & 19,38 & 50,54 & 5,1 \\
\hline 20 & $10-28$ & 8,2 & 3,23 & 7,34 & 24,50 & 15,00 & 1,30 & 40,80 & 2,68 & 0,13 & 0,19 & 20,02 & 53,54 & 5,2 \\
\hline & $28-45$ & 7,9 & 3,61 & 8,20 & - & - & - & - & 2,15 & 0,10 & 0,09 & 21,04 & 55,60 & 5,3 \\
\hline
\end{tabular}


Table 2. Amount of water-resisting aggregates of soil samples under woodland in Pirgulu State Nature Preserve of Azerbaijan

\begin{tabular}{|c|c|c|c|c|c|c|c|c|c|c|c|}
\hline \multicolumn{2}{|c|}{ Soil sections } & \multirow{2}{*}{$>10$} & \multirow{2}{*}{$10-7$} & \multirow{2}{*}{$7-5$} & \multirow{2}{*}{$5-3$} & \multirow{2}{*}{$3-2$} & \multirow{2}{*}{$2-1$} & \multirow{2}{*}{$1-0,5$} & \multirow{2}{*}{$0,5-0,28$} & \multirow{2}{*}{$<0,25$} & \multirow{2}{*}{ Structural coefficient } \\
\hline № & $\mathrm{cm}$ & & & & & & & & & & \\
\hline \multicolumn{12}{|c|}{ Medium clayey, lamella, washed mountain-forest brown } \\
\hline \multirow{2}{*}{1} & $0-12$ & 72,00 & 14,6 & 1,18 & 4,8 & 1,2 & 0,8 & 1,0 & 0,4 & 3,4 & 0,33 \\
\hline & $12-27$ & 75,6 & 12,2 & 4,2 & 3,2 & 1,4 & 1,2 & 0,6 & 0,4 & 1,2 & 0,30 \\
\hline \multirow{3}{*}{18} & $0-6$ & 77,0 & 7,4 & 4,8 & 1,6 & 1,0 & 0,6 & 0,2 & 1,00 & 7,4 & 0,47 \\
\hline & $6-11$ & 90,8 & 1,2 & 2,4 & 2,0 & 1,2 & 1,0 & 0,6 & 0,4 & 0,4 & 0,10 \\
\hline & $11-29$ & 76,6 & 9,8 & 0,8 & 5,2 & 1,8 & 1,2 & 1,0 & 0,4 & 3,2 & 0,25 \\
\hline \multicolumn{12}{|c|}{ Heavy clayey, medium thick, washed mountain-forest brown } \\
\hline \multirow{3}{*}{13} & $0-11$ & 58,8 & 17,6 & 7,5 & 5,5 & 3,2 & 1,9 & 1,5 & 0,7 & 2,3 & 0,64 \\
\hline & $11-29$ & 55,8 & 18,5 & 10,5 & 7,6 & 3,1 & 1,2 & 1,0 & 0,2 & 2,1 & 0,73 \\
\hline & $29-42$ & 52,0 & 21,0 & 14,4 & 7,4 & 0,2 & 1,0 & 2,0 & 0,6 & 1,4 & 0,87 \\
\hline \multirow{3}{*}{14} & $0-10$ & 79,0 & 1,0 & 2,7 & 3,0 & 5,0 & 2,7 & 3,3 & 2,3 & 1,0 & 0,25 \\
\hline & $10-31$ & 63,0 & 14,0 & 11,0 & 7,5 & 1,0 & 0,5 & 1,0 & 0,5 & 1,5 & 0,55 \\
\hline & $31-49$ & 75,8 & 8,4 & 4,2 & 3,4 & 0,8 & 1,0 & 0,2 & 0,6 & 5,6 & 0,23 \\
\hline \multicolumn{12}{|c|}{ Heavy clayey, lamella, washed mountain-forest brown } \\
\hline \multirow{2}{*}{7} & $0-10$ & 59,6 & 14,9 & 12,6 & 4,8 & 3,0 & 1,4 & 0,5 & 0,2 & 3,0 & 0,60 \\
\hline & $10-29$ & 54,2 & 21,8 & 9,4 & 6,6 & 5,2 & 1,5 & 0,3 & 0,3 & 0,7 & 0,82 \\
\hline \multirow{2}{*}{9} & $0-10$ & 62,6 & 10,4 & 4,2 & 6,2 & 0,6 & 5,4 & 0,6 & 0,4 & 9,6 & 0,39 \\
\hline & $10-29$ & 70,2 & 9,9 & 7,6 & 5,0 & 2,8 & 1,7 & 0,7 & 0,3 & 1,8 & 0,39 \\
\hline \multicolumn{12}{|c|}{ Heavy clayey, medium thick, typical mountain-forest brown } \\
\hline \multirow{3}{*}{2} & $0-13$ & 86,2 & 1,1 & 0,7 & 0,9 & 2,2 & 0,2 & 1,8 & 6,2 & 0,7 & 0,15 \\
\hline & $13-30$ & 73,2 & 9,4 & 6,5 & 4,0 & 2,4 & 1,9 & 1,0 & 0,8 & 0,8 & 0,35 \\
\hline & $30-42$ & 68,8 & 10,2 & 7,4 & 4,2 & 2,2 & 1,4 & 0,8 & 0,1 & 1,9 & 0,37 \\
\hline 12 & $0-8$ & 60,3 & 17,9 & 8,8 & 6,0 & 2,4 & 1,8 & 0,7 & 0,3 & 1,8 & 0,61 \\
\hline 12 & $8-21$ & 48,4 & 20,0 & 10,5 & 6,8 & 5,2 & 2,7 & 1,0 & 0,4 & 5,0 & 0,87 \\
\hline & & & & Ligh & $y$, lar & ypica & ntain & $t$ brow & & & \\
\hline 15 & $0-10$ & 88,4 & 4,8 & 1,4 & 1,0 & 1,4 & 0,8 & 0,6 & 0,4 & 1,2 & 0,12 \\
\hline 15 & $10-24$ & 80,5 & 6,4 & 5,2 & 3,1 & 1,0 & 0,6 & 0,4 & 0,2 & 2,6 & 0,20 \\
\hline & $0-8$ & 79,8 & 8,4 & 2,4 & 3,6 & 0,4 & 0,2 & 0,6 & 0,4 & 4,2 & 0,19 \\
\hline 17 & $8-17$ & 68,2 & 4,5 & 4,0 & 3,8 & 2,0 & 7,3 & 3,5 & 3,1 & 1,6 & 0,43 \\
\hline & $17-35$ & 60,6 & 22,8 & 4,8 & 1,6 & 1,0 & 0,6 & 0,2 & 1,0 & 7,4 & 0,47 \\
\hline & & & & Heavy & , lam & rbona & ounta & rest br & & & \\
\hline & $0-12$ & 67,4 & 5,8 & 3,0 & 3,6 & 1,4 & 6,4 & 4,0 & 3,4 & 5,0 & 0,38 \\
\hline 16 & $12-29$ & 86,4 & 7,0 & 3,0 & 1,8 & 0,6 & 0,6 & 0,2 & 0,2 & 0,2 & 0,15 \\
\hline & $29-38$ & 72,4 & 4,4 & 9,0 & 3,0 & 0,6 & 7,0 & 1,4 & 0,2 & 2,0 & 0,34 \\
\hline & $0-11$ & 69,4 & 3,6 & 1,8 & 1,6 & 0,8 & 8,6 & 3,4 & 2,8 & 8,0 & 0,29 \\
\hline 19 & $11-23$ & 73,0 & 9,8 & 3,8 & 4,6 & 2,4 & 1,4 & 1,4 & 2,6 & 1,0 & 0,35 \\
\hline & $23-37$ & 89,2 & 4,0 & 1,6 & 2,4 & 1,6 & 0,4 & 0,2 & 0,2 & 0,4 & 0,12 \\
\hline & & & & ht clay & edium & carbc & $\mathrm{mou}$ & -forest & wn & & \\
\hline & $0-10$ & 64,0 & 10,0 & 5,5 & 6,5 & 7,5 & 1,5 & 2,0 & 2,0 & 1,0 & 1,54 \\
\hline 20 & $10-28$ & 77,4 & 9,0 & 2,6 & 4,0 & 3,8 & 1,2 & 0,6 & 0,6 & 0,8 & 0,28 \\
\hline & $28-45$ & 67,8 & 17,8 & 5,9 & 4,2 & 2,3 & 0,4 & 0,7 & 0,6 & 0,3 & 0,47 \\
\hline
\end{tabular}

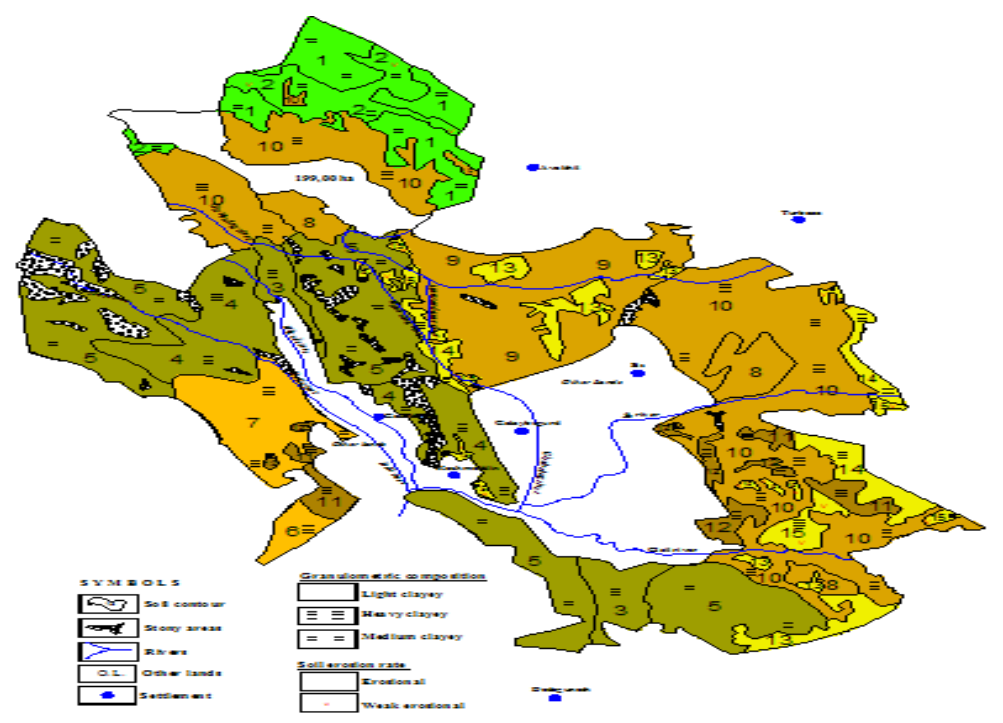

Figure 1. Soil map of Pirgulu State Nature Preserve, on scale $1 \div 25000$ 
Legend

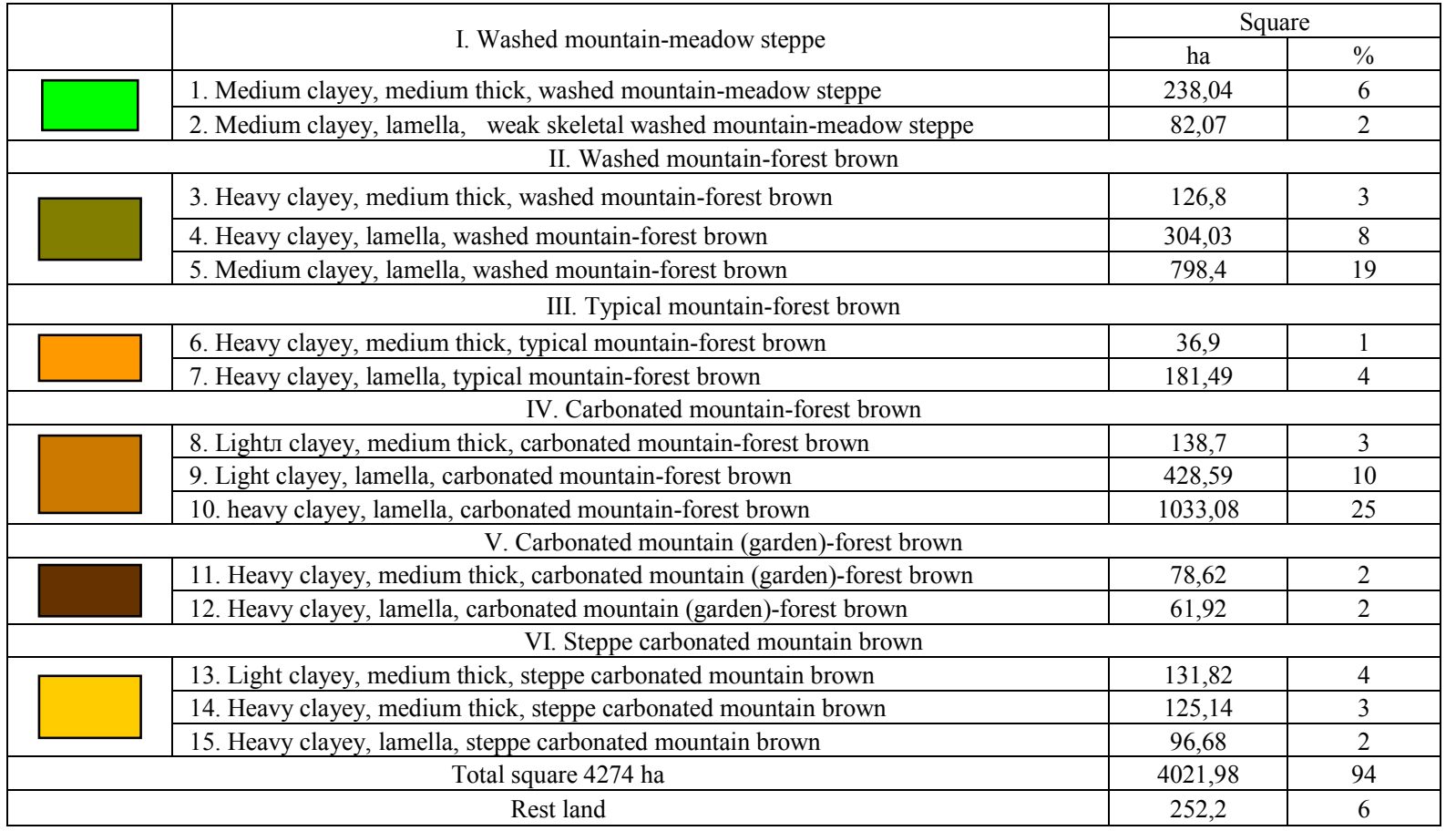

\section{Result and Discussion}

After enlargement the area of the preserve, here the first soil study was realized. While carrying out soil investigations in Pirgulu State Nature Preserve in forest and woodless fields equal 20 soil sections were dug. The depth index of the cross-sections are generally till to $0-50 \mathrm{~cm}$ in the natural condition. The research covers 20 soil cross-sections and 53 soil layers. On the basis of analysis results in cameral treatment due to the granulometric composition, genetic layers' depth, erosion degree of the soil type and sub-types, region's soil taxonomic units were determined. Taking into consideration soil taxonomic units in the preserve region six soil sub-type and fifteen soil kind variety were revealed. Depending on the soil genetic layers' depth in the content of the soil samples humus general nitrogen, general phosphorus, hydroscopic humidity, granulometric content, carbonation, $\mathrm{SAB}$ (Sum of absorbed basis), $\mathrm{pH}$ amount were defined. At the same time soil structure and dry particles' amount were revealed, too. Correspondingly analysis outcome depending on the soil samples' digging direction are accumulated in two groups. There two soil cross-sections in some soil types' contour. Such soil sections are grouped in the same soil sub-type. Analysis indexes of the soil samples from the woodland areas have been given at the following table on soil sub-types.

As it seen from the table $\mathrm{pH}$ index of soil samples from several soil sub-type contours is various. Medium reaction in the second layer of the 2nd and 12th, in 15;17, 16;19 and 20th soil sections is acidic. In the first layer of the rest $1 ; 18$, $13 ; 14,7 ; 9$ and $2 ; 12$ soil sections medium reaction index is alkalotic. Though there is no neutral medium, in alkalotic medium indices are closer to neutral zone. As for $\mathrm{Ca}$ amount general maximum index is 5,66, minimum index consists of 1,90. maximum indice of $\mathrm{CaCO}_{3}$ is 12,86 and minimum indice is 4,32 . SAB indexes cover all soil sections except the third layer of some sections. These soil sections concern to the woodland area, therefore region's soils are rich with humus but in some soil cross-sections this index is some lower. General indices of N, P appear due to humus amount. In this part of the investigating region content of humus consists of mainly humic acid. It is more important factor influencing on the chemical content of humus. According to the granulometric composition, soils are majorly heavy and medium clayey, partly they're light clayey soils. Higroscopic humidity of woodland soils in Pirgulu is 3,1-5,3\%. In several soil sections humidity is more. Thick forest litter gives opprotunity to accumulate atmospheric precipitation and this causes enough higroscopic humidity in woodland soils. That's why rich forest area has great significance in soil fertility indexes. Almost in soil granulometric content formation mentioned factors influences on especially region's geocoenosis. Sizes of the mechanical mixtures in soil content have major impact to the soils' other properties. Granulometric content of the soil sections in the woodland area on soil sections and layers has been given at the following table.

As seen from the table in 34 layers of 13 soil sections, structural coefficient changes between $0,10-1,54$. in the soils having medium clayey, lamella genetic layers at 10 , the highest index is 90,8 , the lowest index is 72,00 .

In 10-0,25 interval these indices change between 1,2-14,6. Even different soil types have the same mechanical content their water resisting aggregates indexes distinguish completely each-other in 10-0,25 interval. 


\section{Conclusions}

After having carried out soil study in woodland area of the preserve, some facts were revealed. Initially being sparse in forest zones was observed and its hazardous influence on the soil cover was determined. Due to the law of the preserve near $70 \%$ territory of Pirgulu State Nature Preserve should have been sylvan, but hewing of the woodland leaded to forest zone decreasing. It stands after woodland, forest soils stay without protection, finally forest soil undergoes erosion and other damages, especially in mountainous region where woodlands have great importance. Because in such areas forest fitomass reduces, distribution of atmospheric precipitations disturb on the slopes. That causes washing of the soils which leads to soil slides on the mountainous area. After the experiments and laboratory analysis, the first soil map of Pirgulu State Nature Preserve was established. From the soil map I dare say that the total territory (4274 ha) covered 4 soil types, 6 soil sub-types and 15 soil kind diversities. The lest territory concerns to the first - washed mountain meadow steppe soil sub-type (8\%), the third - typical mountain-forest brown soil sub-type $(5 \%)$, the fifth - carbonated mountain (garden)-forest brown soil sub-type (4\%) and the rest lands $(6 \%)$. To this soil map all soils, under woodland and woodless areas were taken into consideration. Summarizing the soil study I came into conclusion that protection of Pirgulu State nature Preserve is inescapable, because this preserve was organized for providing work regime Astrophysical observatory with clean air and saving biodiversity of the region.

\section{ACKNOWLEDGMENTS}

This research has been carried out due to two state programs on "alternative and renewable energy application in Azerbaijan" and "Reforestation in the Republic". Also I'm grateful for Dr., Associate Professor Fuad Mammadov because of huge assistance and support in the realization of field work for soil study in Pirgulu State Nature Preserve.

\section{REFERENCES}

[1] U.F. Mammadova. Ecological Estimation of Forest Soils in Azerbaijan. Journal of Ecology and the Natural Environment. vol. 3/№ 6, May 2011, pp. 181-185

[2] U.F. Samadova. Effective Protection of Forest Soils in Azerbaijan. International Journal of Academic Research. vol.1/№1, 2009, pp. 53-58

[3] U.F. Samadova. Open Bonitation Scale of soils under woodland and woodless areas (Shamakhi region). Ecology and Water Industry. № 4/2009, pp. 30-34

[4] U.F Samadova. Solar and Wind Energy Application for the Woods and Forest Soil' s Protection // Renewable Energy Congress X, Glasgow, Scotland, 19-25 July 2008, pp 512-514

[5] G.Sh.Mammadov,M. Y. Khalilov Azerbaijan Forests. Baki : «Elm», 2002. p. 472

[6] U.F. Mammadova. Ecological Estimation of Forest soils in Azerbaijan. Journal of Ecology and Natural Environment. May 2011,Vol. 3(5), pp181-185 